\title{
INFORMIRANI PRISTANAK - PRAVNI OKVIR ZA ZAŠTITU PRAVA PACIJENATA I SUDIONIKA ISTRAŽIVANJA
}

\author{
Marin Šunjić ${ }^{1}$, Ivana Soldo ${ }^{1}$, Franjo Liška ${ }^{2}$, Josip Šimić ${ }^{3}$ \\ ${ }^{1}$ Sveučilište u Mostaru Medicinski fakultet \\ ${ }^{2}$ Zdravstveno veleučilište Zagreb \\ ${ }^{3}$ Sveučilište u Mostaru Fakultet zdravstvenih studija
}

Rad je primljen 12.04.2021. Rad je recenziran 23.04.2021. Rad je prihvaćen 29.04.2021.

\begin{abstract}
SAŽETAK
Informirani pristanak, kao jedno od prava pacijenata, predstavlja slobodno očitovanje volje pacijenta odnosno njegovu suglasnost za provođenje predložene medicinske mjere ili sudjelovanja u istraživanju, a za njegovu valjanost potrebni su kompetentnost bolesnika, adekvatnost informacije i dobrovoljnost.

Europska unija na cjelokupnom svom prostoru nastoji regulirati i ujednačiti prava pacijenata, odnosno učiniti da prava pacijenata ne smiju biti određena granicama. Područje zdravstva, a samim time i informiranog pristanka pacijenata u Bosni i Hercegovini u nadležnosti je entiteta Republika Srpska, podijeljenoj nadležnosti entiteta i županija u Federaciji Bosne i Hercegovine, i u nadležnosti Brčko Distrikta Bosne i Hercegovine. Iako nema zakona na državnom nivou koji reguliraju pravnu zaštitu i prava pacijenata, Vijeće ministara BiH 2003. godine donijelo je Odluku o procedurama i postupku usklađivanja zakonodavstva BiH s ACQUIS COMMUNAUTAIRE (usklađivanje propisa BiH s propisima Europske unije), a 2010. godine Odluku o usvajanju dokumenta aktivnosti za integraciju zdravstvenog sektora BiH u Europsku uniju. Prava pacijenata u Bosni i Hercegovini razlikuju od entiteta do entiteta i distrikta, odnosno od županije do županije u FBiH, što svakako predstavlja problem i nejednakost.
\end{abstract}

Ključne riječi: informirani pristanak; pravne norme; biomedicinska istraživanja; pacijenti; Bosna i Hercegovina

Osoba za razmjenu informacija:

Marin Šunjić, dipl. iur.

E-mail: marin.sunjic@mef. sum.ba 


\section{UVOD}

Informirani pristanak je izjava pacijenta ili ispitanika nekog znanstvenog istraživanja koja liječnika ili medicinskog istraživača opunomoćuje da provede određene mjere, terapiju ili da uključi ispitanika $u$ istraživački protokol (1).

Informirani pristanak je "medicinsko-etičko područje koje povezuje temeljnu etičku spoznaju s kliničkom praksom i odnosom prema bolesniku u kojem dolazi do izražaja analiza i vrjednovanje spoznajnog medicinskog i etičkog potencijala u pitanjima: poštovanja bolesnikove osobnosti, slobode mišljenja i odlučivanja, zaštite prava bolesnika u medicinskom postupku i biomedicinskom istraživanju, sudjelovanja rodbine, skrbnika ili bolesnikova zastupnika u etičkoj analizi i odlučivanju o bolesnikovu stanju, odnosa prema djeci, bolesnicima i osobama sa smanjenom sposobnošću rasuđivanja, usuglašavanja bolesnika i ispitanika za postupak i istraživanje, te komunikacije između zdravstvenih djelatnika i bolesnika" (2). Da bi informirani pristanak bio valjan, neophodno je da budu ispunjeni sljedeći uvjeti: kompetentnost bolesnika, adekvatnost informacije i dobrovoljnost.

Kompetentnost je sposobnost osobe da razumije informaciju relevantnu za donošenje odluke, da shvati važnost i značaj informacije $u$ danoj situaciji, da zaključuje koristeći informaciju, da izabere i izrazi svoj izbor. Ako je bolesnik nekompetentan, pravo odlučivanja u njegovo ime steći će najbliži član obitelji ili staratelj kojeg je dodijelio sud. Adekvatnost informacije odnosi se na moralnu dužnost liječnika da bolesniku na njemu razumljiv način objasni kako će se intervencija provesti, koje su njene moguće posljedice, da mu predoči moguću alternativu i njezine posljedice. Dobra komunikacija između liječnika i bolesnika ima ključni značaj za ovaj vid informiranog pristanka.

Dobrovoljnost podrazumijeva da bolesnik donosi odluku samovoljno, bez tuđeg utjecaja, prinude, obmane i manipulacije. Dobrovoljnost lako može biti narušena u uvjetima medicinske prakse, prije svega zbog nerazmjera u znanju i moći između liječnika i bolesnika, zatim u slučajevima izrazito vulnerabilnih bolesnika kao što su mentalno ometene osobe, psihijatrijski bolesnici, zatvorenici, djeca, beskućnici(3).

\section{Informirani pristanak i biomedicinska istraživanja}

Iako je uobičajeno očekivati etičku odgovornost i zakonsku dužnost zdravstvenih radnika da od pacijenata i sudionika istraživanja dobiju valjani informirani pristanak, pristanak u nekim slučajevima nije dobro protumačen ili dobro dokumentiran $\mathrm{u}$ praksi (4). Sve veći broj dokaza sugerira da postupak informirane suglasnosti u potpunosti ne zadovoljava potrebe sudionika kliničkog istraživanja(4-6). Važno je naglasiti i različit pristup kada je u pitanju informirani pristanak sudionika u liječničkoj praksi $\mathrm{u}$ odnosu na pristanak u okviru biomedicinskih istraživanja. Liječniku je očekivano važna zdravstvena dobrobit bolesnika, a istražitelju je često važan „sudionik“ u istraživanju, ponekad „što više to bolje“ i s različitom svrhom istraživanja. Pri istraživanju često nije jasno kako će se ono odraziti na zdravlje sudionika u istraživanju (7). Prethodni rezultati istraživanja pokazuju da se $40 \%$ do $80 \%$ sudionika istraživanja, za koje je u početku ocijenjeno da mogu dati pristanak, nije podsjetilo na jedan ili više potrebnih elemenata podataka o pristanku (8-10). Biomedicinska istraživanja koja uključuju intervencije ne smiju se dopustiti ako potencijalni sudionik nije dao svoj pristanak (za osobe koje nisu sposobne dati pristanak potreban je zakonski zastupnik). Da bi pristanak bio pravovaljan, osoba koja ga daje mora biti adekvatno i slobodna u davanju pristanka. (7). Treba naglasiti i načelo autonomije, koje se, kada su u pitanju biomedicinska istraživanja, provodi putem slobodnog i informiranog pristanka. Pristanak na istraživanje se u svakom trenutku može povući. Kada je u pitanju informirani pristanak, unatoč široko rasprostranjenom slaganju oko pravne i etičke prikladnosti općeg pravila informiranog pristanka za istraživanja na ljudima, postoje primjeri vrlo specifičnih situacija u kojima stoje i razlozi za izuzeće (11). Primjer su biomedicinska istraživanja koja se mogu provoditi samo na onesposobljenim pacijentima, poput istraživanja u vezi oživljavanja pacijenta (12). Potencijalni sudionik u istraživanju stoga mora dobiti primjerene, precizne i razumljive informacije o istraživačkom projektu prije no što se od njega zatraži da donese odluku o sudjelovanju. Kako bi se osobi omogućilo donošenje informirane 
odluke, informacije moraju sadržavati razumljiv opis predviđenih postupaka, njihovu svrhu, te predvidljive rizike i dobrobiti (7).

\section{PRAVNI OKVIR U EUROPSKOJ UNIJII REPUBLICI HRVATSKOJ}

Nürnberški kodeks, iz kolovoza 1947. godine, u deset načela ujedinjuje etičke principe Hipokratove zakletve bazirane na liječnika, te principe autonomije bazirane na pravo ljudskog bića na pristanak i odustajanje od sudjelovanja $u$ znanstvenim istraživanjima i medicinskim postupcima.

Etički stavovi o problemima u vezi s medicinskim istraživanjima koja se provode na ljudima intenzivno se razmatraju od vremena nakon II. svjetskog rata pa sve do danas. To je vjerojatno uvjetovano naglim razvojem terapijskih i dijagnostičkih mogućnosti u modernoj medicini, ali i lošim iskustvima iz prethodnog burnog razdoblja. Kao jedan od značajnih rezultata izgrađenih etičkih stavova u vezi s tim problemima. na 18. sastanku Svjetskog udruženja liječnika koje je bilo održano u Helsinkiju u Finskoj 1964. godine, donesena je tzv. Helsinška deklaracija koja sadržava preporuke za liječnike koji rade u kliničkim istraživanjima. Na 29. skupštini Svjetskog udruženja liječnika u Tokiju (Japan) 1975. godine predložena i prihvaćena nova varijanta tzv. tokijska revizija Helsinške deklaracije(13).

Deklaracijom o promoviranju prava pacijenata $\mathrm{u}$ Europi (Thedeclaration onthepromotionofpatients'srightsin Europe) iz Amsterdama (1994. godine), uređena su ljudska prava i vrijednosti u području zdravstvene zaštite (14). Prema odredbama ove deklaracije, svatko ima pravo da ga se poštuje kao ljudsko biće, pravo na očuvanje fizičkog i mentalnog integriteta i zaštitu svoje ličnosti, pravo na poštivanje svojih moralnih i kulturnih vrijednosti, te vjerskih i filozofskih uvjerenja, kao i najveći mogući stupanj zaštite svoga zdravlja (15).

$\mathrm{Na}$ navedeni dokumentnadovezujese veliki broj drugih dokumenata, među kojima je svakako i Europska konvencija o ljudskim pravima. Deklaracija predstavlja osnovu za donošenje propisa iz područja zaštite prava pacijenata u mnogim zemljama Europske Unije. Također, ovaj dokument predstavlja osnov i zemljama koje nisu članice Europske uni- je ali su u postupku usklađivanja svojih propisa $s$ propisima Europske Unije, što je slučaj i u Bosni i Hercegovini.

Konvencija o ljudskim pravima u biomedicini poznatiji je naziv dokumenta Konvencija o zaštiti ljudskih prava i dostojanstva ljudskih bića s posebnim naglaskom na primjenu u biologiji i medicini. Konvenciju je 04. travnja 1997. godine u Oviedu donijelo Vijeće Europete ponudilo na potpisivanje i usvajanje zemljama članicama (16).

Europskom poveljom o pravima pacijenata, koja je donesena 2002. godine u Rimu, utvrđena su sljedeća prava koja uživaju pacijenti: pravo na preventivne mjere, pravo na pristup zdravstvenim uslugama, pravo na sve vrste informacija u vezi s njegovim zdravljem i postupkom izbora liječenja, pravo na pristanak kao aktivno učešće u liječenju, pravo na izbor načina liječenja i dijagnostike, pravo na privatnost i povjerljivost, poštivanje pacijentovog vremena, pravo na praćenje standarda kvalitete, odnosno pristup visokokvalitetnim standardima usluga, pravo na sigurnost, odnosno da bude pošteđen štete uzrokovane lošim funkcioniranjem zdravstvenog sustava, medicinski loše prakse i grešaka, kao i pravo na pristup zdravstvenim uslugama koje ispunjavaju standarde sigurnosti, pravo na inovaciju, odnosno pristup inovativnim načinima liječenja i dijagnostike, pravo na izbjegavanje nepotrebne patnje $\mathrm{i}$ bola, pravo na osobni tretman odnosno na liječenje i dijagnostiku prilagođenu njegovim potrebama, na žalbu kad god da je pretrpio štetu ili je tražio informaciju, na kompenzaciju unutar razumnog vremena kad god su pretrpjeli štetu ili su bili izloženi fizičkoj, moralnoj ili psihičkoj povredi uzrokovanoj postupcima pružanja zdravstvene usluge(17).

Direktiva 2011/24/EU o primjeni prava pacijenata u prekograničnoj zdravstvenoj skrbi primjenjuje se od 24. travnja 2011. godine, a trebala je ući u zakonodavstvo država EU-a do 25. listopada 2013. godine. Ovom direktivom utvrđuju se uvjeti pod kojima pacijent može putovati u drugu zemlju EU-a kako bi dobio sigurnu i visokokvalitetnu medicinsku skrb a da mu troškove nadoknađuje vlastiti sustav zdravstvenog osiguranja te potiče suradnju među nacionalnim sustavima zdravstvene zaštite. Prva od ključnih točaka Direktivejeste da zemlja EU-a koja 
pruža liječenje mora osigurati, između ostaloga, da pacijentima budu dostupne sve potrebne informacije kako bi mogli donijeti informiranu odluku, uključujući informacije o mogućnostima liječenja, dostupnosti, kvaliteti i sigurnosti zdravstvene zaštite koju pružaju, o cijenama, o stanju stvari u vezi s njihovim odobrenjem ili prijavom (18).

Što se tiče Republike Hrvatske, Zakonom o zaštiti prava pacijenata Republike Hrvatskeodređuju se prava pacijenata prilikom korištenja zdravstvene zaštite te način zaštite i promicanja tih prava. Navedeni Zakon, između ostaloga, u člancima 16. -21. uređuje pravo na prihvaćanje ili odbijanje pojedinoga dijagnostičkog, odnosno terapijskog postupka, zaštitu pacijenta koji nije sposoban dati pristanak izaštitu pacijenta nad kojim se obavlja znanstveno istraživanje (19).

Pravilnikom o obrascu suglasnosti te obrascu izjave o odbijanju pojedinog dijagnostičkog, odnosno terapijskog postupka uređuje se sadržaj obrasca suglasnosti kojom se prihvaća pojedini preporučeni dijagnostički, odnosno terapijski postupak te sadržaj obrasca izjave o odbijanju pojedinog preporučenog dijagnostičkog, odnosno terapijskog postupka u zdravstvenim ustanovama, trgovačkim društvima koja obavljaju zdravstvenu djelatnost te kod privatnih zdravstvenih radnika (20).

\section{PRAVNI OKVIR U BOSNI I HERCEGOVINI}

Područje zdravstva u Bosni i Hercegovini (BiH) u nadležnosti je entiteta Republika Srpska, podijeljenoj nadležnosti entiteta i županija u Federaciji $\mathrm{BiH}(\mathrm{FBiH})$, i u nadležnosti Brčko Distrikta BiH. Iako nema zakona na državnom nivou koji reguliraju pravnu zaštitu i prava pacijenata, Vijeće ministara $\mathrm{BiH}$ 2003. godine je donijelo Odluku o procedurama i postupku usklađivanja zakonodavstva $\mathrm{BiH}$ s ACQUIS COMMUNAUTAIRE (usklađivanje propisa $\mathrm{BiH}$ s propisima Europske unije), a 2010. godine Odluku o usvajanju dokumenta aktivnosti za integraciju zdravstvenog sektora $\mathrm{BiH}$ u Europsku uniju (21).

Prava, obveze i odgovornosti pacijenatau $\mathrm{FBiH}$ uređena su Zakonom o zdravstvenoj zaštiti, Zakonom o zdravstvenom osiguranju, Zakonom o li- ječništvui Zakonom o pravima, obavezama i odgovornostima pacijenta, te Kodeksom medicinske etike i deontologije Liječničke komore FBiH (22-26).

U Republici Srpskoj prava i obaveze pacijenta propisane su Zakonom o zdravstvenoj zaštiti, Zakonom o zdravstvenom osiguranju i Zakonom o pravima pacijenata (27-29).

U Brčko distriktu prava pacijenata regulirana su Zakonom o zdravstvenoj zaštiti u Brčko distriktu $\mathrm{BiH}(30)$.

Najznačajniji pravni akt koji regulira područje prava pacijenata u $\mathrm{FBiH}$, pa samim tim i njihove suglasnosti odnosno informiranog pristanka za poduzimanje određenim medicinskih mjera svakako je Zakon o pravima, obavezama i odgovornostima pacijenata $\mathrm{FBiH}$, koji prepoznaje i definira pravo na samoodlučivanje i pristanak, te daje pravo da pacijent može slobodno odlučivati o svemu što se tiče njegovog života i zdravlja, osim u slučajevima kada to izravno ugrožava život i zdravlje drugih. Nadalje, bez pristanka pacijenta ne smije se, u pravilu, nad njim poduzeti nikakva medicinska mjera.

Spomenuti Zakon određuje da pacijent daje pristanak na predloženu određenu medicinsku mjeru izričito, usmenim ili pisanim putem, te da je pisani pristanak pacijenta obvezan za invazivne dijagnostičke zahvate i operativne zahvate. Svoj pristanak na predloženu medicinsku mjeru pacijent može usmeno opozvati sve dok ne započne njeno izvođenje.

Zakon daje mogućnost da pacijent ima pravo odrediti osobu koja će u njegovo ime dati pristanak, odnosno koje će biti obaviješteno umjesto pacijenta o poduzimanju medicinskih mjera, u slučaju da pacijent postane nesposoban da donese odluku o pristanku.

Zakonom o liječništvu FBiH uređuje se pojam, organizacija i uvjeti za obavljanje liječničkog zvanja, djelovanje liječnika kao osnovnog, samostalnog i odgovornog nositelja zdravstvene djelatnosti koja je od posebnog interesa za $\mathrm{FBiH}$ i koja osigurava zdravstvenu zaštitu svakom pojedincu i cjelokupnom stanovništvu $\mathrm{FBiH}$, kao i prava, obaveze i odgovornosti liječnika, ali se i utvrđuje da je liječnik obvezan pacijentu ili osobi koju pacijent odredi dati potrebne informacije i obavještenja koja su paci- 
jentu potrebna kako bi pacijent donio informiranu odluku da pristane ili ne pristane na predloženu medicinsku mjeru. Svi postupci medicinske prevencije, dijagnostike i liječenja moraju se planirati i provoditi tako da se očuva ljudsko dostojanstvo, integritet osobe i prava pacijenata u skladu s propisima o pravima, obavezama i odgovornostima pacijenata, a posebno pravo na informiranost, obaviještenost i sudjelovanje u liječenju, kao i pravo na samoodlučivanje i pristanak.

Uz postojanje zakonske obveze utvrđene u članku 19. stavku (5) Zakona o pravima, obavezama i odgovornostima pacijenata $\mathrm{FBiH}$, Federalno ministarstvo zdravstva donijelo je Pravilnik o obrascu suglasnosti, odnosno pristanka pacijenta na predloženu medicinsku mjeru, te obrascu izjave o odbijanju pojedine medicinske mjere kojim se uređuje sadržaj obrasca suglasnosti, odnosno pristanka pacijenta na pojedinu predloženu medicinsku mjeru kao i sadržaj obrasca izjave o odbijanju pojedine medicinske mjere.

Obrazac suglasnosti, odnosno obrazac izjave o odbijanju predložene medicinske mjere pacijent potpisuje nakon što je dobio dovoljno obuhvatno, točno i pravovremeno obavještenje u skladu $s$ propisima o pravima, obavezama i odgovornostima pacijenata. Obuhvatnost obavještavanja cijeni se u svakom posebnom slučaju prema mogućnosti da pacijent nadležnom doktoru medicine/dentalne medicine može postavljati pitanja nakon ili u tijeku obavještavanja i na njih dobivati njemu razumljive odgovore. Točnost obavještavanja zasniva se na spoznatim medicinskim i drugim činjenicama tijekom pregleda i liječenja pacijenta.

Pravovremenost obavještenja definira se kao obavještavanje pacijenta o kliničkim nalazima i predloženim medicinskim mjerama, ostavljajući pacijentu najmanje 24 sata od davanja obavještenja, da može razmisliti o svojoj odluci, izuzev u hitnim slučajevima. Obavještenje daje nadležni doktor medicine/dentalne medicine, u skladu s propisima o pravima, obavezama i odgovornostima pacijenata $u$ usmenoj ili pismenoj formi.

U članku 6. naprijed navedenog Pravilnika taksativno je pobrojano i propisano da obavještenje sadrži sljedeće:
- obavještenje pacijenta o pravu na odlučivanje o pristanku, odnosno odbijanju predložene medicinske mjere, kao i o pravu na povlačenje pristanka,

- obavještenje pacijenta o pravu na odbijanje prijema obavještenja, kao i mogućnošću da odredi osobu koja će primiti puno obavještenje u njegovo ime,

- opis i objašnjenje dijagnoze i prognoze bolesti,

- opis cilja i koristi od predložene medicinske mjere (termin),

- opis i objašnjenje o vrsti i vjerojatnoći mogućih rizika, bolnih i drugih sporednih ili trajnih posljedica, a u skladu sa stručnim stavovima,

- opis i objašnjenje mogućih promjena stanja poslije poduzimanja predložene medicinske mjere, kao i mogućim nužnim promjenama u načinu života,

- objašnjenje djelovanja lijekova i mogućim nuspojavama tog lijeka,

- upoznavanje s drugim mogućim metodama liječenja s opisom koristi i rizika svake od tih metoda, uključujući i efekt neliječenja,

- objašnjenje o daljem tijeku pružanja zdravstvene zaštite koji uključuje druge medicinske mjere i ostalim uslugama koje su na raspolaganju pacijentu, a ne pripadaju isključivo medicinskim mjerama,

- informacije o organizacijskim aspektima njegovog liječenja,

- informacije o načinu zakazivanja pregleda, dijagnostičkih i terapijskih procedura i jasno objašnjenje u slučaju odgađanja ili odustajanja od medicinske mjere,

- o listi čekanja, vremenu čekanja, načinu formiranja liste čekanja, kao i s terminom izvođenja

- medicinske mjere, odnosno informacije o načinu zakazivanja termina,

- informacija o zakazanom terminu za predloženu medicinsku mjeru,

- pravima iz zdravstvenog osiguranja i postupcima za ostvarivanje tih prava (31). 
Suvremena znanost izvor je svih objektivnih ljudskih dobrobiti (32). Za napredak biomedicinskog znanja važno je jasno pravno regulirati područje informiranog pristanka u odnosu na biomedicinska istraživanja. U vremenu povećane mogućnosti razmjene istraživačkih podataka kliničkih istraživanja pravno reguliranje ovog područja ubrzalo bi i stvaranje biomedicinskog znanja, povećala bi se pouzdanost dokaza i pojačao integritet istraživanja (33-36).

\section{ZAKLJUČAK}

Najznačajniji pravni akt koji regulira područje prava pacijenata u $\mathrm{FBiH}$, pa samim tim i njihove suglasnosti odnosno informiranog pristanka za poduzimanje određenim medicinskih mjera svakako je Zakon o pravima, obavezama i odgovornostima pacijenata $\mathrm{FBiH}$. Federalno ministarstvo zdravstva donijelo je Pravilnik o obrascu suglasnosti, odnosno pristanka pacijenta na predloženu medicinsku mjeru, te obrascu izjave o odbijanju pojedine medicinske mjere kojim se uređuje sadržaj obrasca suglasnosti, odnosno pristanka pacijenta na pojedinu predloženu medicinsku mjeru kao i sadržaj obrasca izjave o odbijanju pojedine medicinske mjere.

U zakonodavstvu BiH otežavajuću okolnost svakako predstavlja i činjenica da je područje zdravstva u BiH u nadležnosti entiteta Republika Srpska, podijeljenoj nadležnosti entiteta i županija $\mathrm{FBiH}$, i u nadležnosti Brčko Distrikta BiH. Uzimajući u obzir naprijed navedeno dolazimo do zaključka da se prava pacijenata u BiHrazlikuju od entiteta do entiteta i distrikta, a konkretno u $\mathrm{FBiH}$ prava pacijenata razlikuju se od županije do županije, što svakako predstavlja svojevrsni problem jer bi ista trebala biti uređena $i$ jednaka na razini ne samo entiteta nego cijele BiH. Trenutno ustavno uređenje $\mathrm{BiH}$ ne dozvoljava zakonsko reguliranje prava pacijenata na državnoj razini, što dovodi do zaključka da postoji prostor za napredak prava pacijenata.

\section{LITERATURA}

1. Sorta Bilajac I. Informirani pristanak - konceptualni, empirijski i normativni problemi. Medicina fiuminensis. 2011; 47(1): 37-47.

2. Šegota I. Nova medicinska etika (bioetika). Rijeka: Medicinski fakultet u Rijeci, 1994.

3. Jeremić V. Informirani pristanak: komunikacija između liječnika i bolesnika, 2013; 4(7): 528.

4. Lorell BH, Mikita JS, Anderson A, Hallinan $\mathrm{ZP}$, Forrest A. Informed consent in clinical research: Consensus recommendations for reform identified by an expert interview panel. Clin Trials. 2015; 12(6): 692-5. doi: 10. $1177 / 1740774515594362$.

5. Meade CD. Improving understanding of the informed consent process and document. Semin Oncol Nurs 1999; 15: 124-137.

6. Nishimura A, Carey J, Erwin PJ, et al. Improving understanding in the research informed consent process: a systematic review of 54 interventions tested in randomized control trials. BMC Med Ethics 2013; 14: 28.

7. Upravni odbor za bioetiku Vijeća Europe (2010) Smjernice za članove Istraživačkih etičkih povjerenstava; Stručna skupina za biomedicinska istraživanja (CDBI-CO-GT2)

8. Mukherjee A, Livinski AA, Millum J, Chamut S, Boroumand S, Iafolla TJ, Adesanya MR, Dye BA. Informed consent in dental care and research for the older adult population: A systematic review. J Am Dent Assoc. 2017; 148(4): 211-220.

9. Wendler D. Can we ensure that all research subjects give valid consent? Arch Intern Med. 2004; 164(20): 2201-2204.

10. Joffe S, Cook EF, Cleary PD, Clark JW, Weeks JC. Quality of informed consent in cancer clinical trials: a cross-sectional survey. Lancet. 2001; 358(9295): 1772-1777.

11. Rebers S, Aaronson NK, van Leeuwen FE, Schmidt MK. Exceptions to the rule of informed consent for research with an intervention. BMC Med Ethics. 2016; 6: 17: 9.

12. Biros M. Research without consent: Exception from and waiver of informed consent in 
resuscitation research. Sci Eng Ethics. 2007; 13: 361-9.

13. Milorad M. Etički standardi kod medicinskih istraživanja na ljudima (Ethicalstandardsin human medicalresearch).

14. World Health Organization. A declaration on the promotion of patients' rights in europe; Dostupno na: http: //www. who. int/genomics/public/eu_declaration1994.pdf.

15. COUNCIL OF EUROPE. European Treaties. ETS No. 164. Convention for the Protection of Human Rights and Dignity of the Human being with Regard to the Application of Biology and Medicine: Convention on Human Rights and Biomedicine. Oviedo, 04. IV. 1997.

16. Dostupno na https//www. pravopacijenta. ba `Evropska povelja o pravima pacijenta.

17. Directive 2011/24/EU of the European Parliament and of the Councilof 9 March 2011 on the Application of Patients' Rights in Cross-border Healthcare. Official Journal of the European UnionL 88/45. 4. 4. 2011.

18. Zakon o zaštiti prava pacijenata Republike Hrvatske ("Narodne novine", broj 169/04 i 37/08).

19. Pravilnik o obrascu suglasnosti te obrascu izjave o odbijanju pojedinog dijagnostičkog, odnosno terapijskog postupka("Narodne novine", broj 10/08).

20. Odluka o procedurama i postupku uskladivanja zakonodavstva $\mathrm{BiH}$ s ACQUIS COMMUNAUTAIRE („Službeni glasnik $\mathrm{BiH}^{\prime}$, broj 44/03).

21. Odluka o usvajanju dokumenta aktivnosti za integraciju zdravstvenog sektora $\mathrm{BiH} \mathrm{u} \mathrm{Eu-}$ ropsku uniju („Službeni glasnik BIH“, broj 18/11).

22. Zakon o zdravstvenoj zaštiti ("Službene novine Federacije BiH”, br. 46/10 i 75/13).

23. Zakon o zdravstvenom osiguranju ("Službene novine Federacije $\mathrm{BiH”,} \mathrm{br.} \mathrm{30/97,} \mathrm{7/02,}$ 70/08, 48/11 i 36/18).

24. Zakon o liječništvu FBiH ("Službene novine FBiH", 56/13).
25. Zakon o pravima, obavezama i odgovornostima pacijenta ("Službene novine Federacije BiH”, broj 40/10).

26. Kodeks medicinske etike i deontologije Liječničke komore Federacije BiH (Broj: 01$72 / 15$ od 18. travnja 2015. godine).

27. Zakon o zdravstvenoj zaštiti ("Službene glasnik Republike Srpske”, broj: 106/09, 44/15).

28. Zakon o zdravstvenom osiguranju ("Službene glasnik Republike Srpske”, broj: 18/99, 51/01, 70/01, 51/03, 57/03, 17/08, 01/09, 106/09, 110/16, 94/19 i 44/20).

29. Zakon o pravima pacijenata ("Službene glasnik Republike Srpske”, broj: 45/13 i 25/19).

30. Zakon o zdravstvenoj zaštiti u Brčko distriktu Bosne i Hercegovine („Službeni glasnik Brčko distrikta BiH”, br: 52/18).

31. Pravilnik o obrascu suglasnosti, odnosno pristanka pacijenta na predloženu medicinsku mjeru, te obrascu izjave o odbijanju pojedine medicinske mjere ("Službene novine FBiH", 95/13).

32. Mimica M, Babić D, Vasilj I, Piel G. Važnost i značaj znanosti na fakultetu zdravstvenih studija. Zdravstveni glasnik 2015; 1: 9-12.

33. Šimić J, Babić D. Znanstvena komunikacija u biomedicini i zdravstvu. Zdravstveni glasnik. 2018; 2: 68-70.

34. Krleža-Jerić, K., Gabelica M, Banzi R, Krnić-Martinić M, Pulido B, Mahmić-Kaknjo M, Reverie L, Šimić J, Utrobičić A, Hrgović I. IMPACT Observatory: tracking the evolution of clinical trial data sharing and research integrity. Biochemia Medica. 2016; 26: 308-17.

35. Mahmić-Kaknjo M, Šimić J, Krleža-Jerić K. Setting the IMPACT (IMProve Access to Clinical Trial data) Observatory baseline. Biochemia Medica. 2018; 28(1): 7-15.

36. Šimić J, Tomić V, Vukojević M. Lokalna znanstvena infrastruktura u kontekstu zaštite od pandemije COVID-19. Zdravstveni glasnik. 2020; 6: 19-24. 


\title{
INFORMED CONSENT - LEGAL FRAMEWORK FOR THE PROTECTION OF PATIENTS' AND RESEARCH PARTICIPANTS' RIGHTS
}

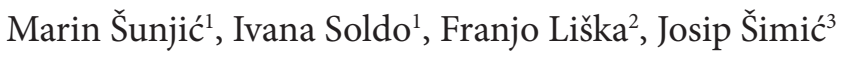 \\ ${ }^{1}$ School of Medicine University of Mostar \\ ${ }^{2}$ University of Applied Health Sciences Zagreb \\ ${ }^{3}$ Faculty of Health Studies University of Mostar
}

\begin{abstract}
Informed consent, as one of the patients' rights, is a free expression of the patient's will or consent to implement the proposed medical measure or participation in research, and its validity requires patient competence, adequacy of information and voluntary nature.

The European Union strives to regulate and harmonize patients' rights throughout its territory, that is, it tries to ensure that patients' rights must not be determined according to borders. The field of health care and therefore informed consent of patients in Bosnia and Herzegovina are under jurisdiction of the entity of Republika Srpska, shared jurisdiction of entity and cantons of the Federation of Bosnia and Herzegovina, and the jurisdiction of the Brčko District of Bosnia and Herzegovina. Although there is no law at state level that regulates legal protection and patients' rights, in 2003 the Council of Ministers of Bosnia and Herzegovina adopted a Decision on procedure of harmonizing BiH legislation with EU ACQUIS COMMUNAUTAIRE, and in 2010 the Decision on the adoption of the document Activities for the Integration of the Health Sector of Bosnia and Herzegovina into the European Union'. Patients' rights in Bosnia and Herzegovina vary from entity to entity and district, and from canton to canton in the $\mathrm{FBiH}$, which certainly represents a problem and inequality.
\end{abstract}

Key words: informed consent; legal norms; biomedical research; patients; Bosnia and Herzegovina

Correspondence:

Marin Šunjić, LL. M

E-mail: marin.sunjic@mef.sum.ba 